\title{
VIAGEM EDUCACIONAL AO URUGUAI EM 1913: IMPRESSÕES DOS PROFESSORES RIO-GRANDENSES ACERCA DAS ESCOLAS DE MONTEVIDÉO'
}

\author{
DOI: http://dx.doi.org/10.1590/2236-3459/60766
}

\author{
Caroline Braga Michel \\ Universidade Federal de Pelotas, Brasil.
}

Eduardo Arriada

Universidade Federal de Pelotas, Brasil.

$\cos 80$

\begin{abstract}
Resumo
O presente artigo analisa as impressões do grupo de professores rio-grandenses que viajou, designado pelas autoridades gaúchas, ao Uruguai no ano de 1913 com o objetivo de conhecer o sistema educacional uruguaio para qualificar o ensino gaúcho. Esses educadores registraram suas impressões e observações acerca das visitas realizadas nas instituições de ensino uruguaias em um Relatório Oficial, composto por cinco partes. A análise, de cunho documental, evidenciou, a partir desse registro, que havia similaridades entre os dois contextos educacionais e ainda, por um lado certa idealização da comissão rio-grandense ao modelo uruguaio e, por outro, a constatação de excelência do método João de Deus utilizado no Rio Grande do Sul.

Palavras-chave: missão educacional; Rio Grande do Sul; Uruguai.
\end{abstract}

\section{EDUCATIONAL MISSION TO URUGUAY IN 1913: THE IMPRESSIONS OF TEACHERS FROM THE STATE OF RIO GRANDE DO SUL ABOUT SCHOOLS IN MONTEVIDEO}

\begin{abstract}
This study aims at discussing the impressions of the group of Brazilian teachers from the State of Rio Grande do Sul who traveled to Uruguay, as designated by the RS authorities, in 1913, to know the Uruguayan educational system in order to qualify the education in RS. These educators recorded their impressions and observations about the visits in the Uruguayan educational institutions in a White Paper, composed of five parts. The analysis of such record, primarily on documentary evidence, showed that there were similarities between the two educational contexts.
\end{abstract}

\footnotetext{
${ }^{1}$ Uma primeira versão deste trabalho foi apresentada no $21^{\mathrm{a}}$ encontro da Asphe realizado na Universidade de Caxias do Sul - UCS -, de 31 de agosto a 2 de setembro de 2015.

ก. 51

Jan./abr., 2017

p. $253-270$
} 
Thus, a certain idealization by the Brazilian commission with regard to the Uruguayan model was found together with the excellence of the João de Deus method used in RS.

Key-words: educational Mission, State of Rio Grande do Sul, Uruguay.

\section{VIAJE EDUCACIONAL A URUGUAY EN 1913: IMPRESIONES DE LOS PROFESORES RÍO-GRANDENSES ACERCA DE LAS ESCUELAS DE MONTEVIDEO}

\section{Resumen}

El presente artículo analiza las impresiones del grupo de profesores río-grandenses que viajó, designado por las autoridades gauchas, a Uruguay en el año de 1913 con el objetivo de conocer el sistema educacional uruguayo para cualificar la enseñanza gaucha. Eses educadores registraron sus impresiones y observaciones acerca de las visitas realizadas en las instituciones de enseñanza uruguayas en un Informe Oficial, compuesto por cinco partes. El análisis, de cuño documental, evidenció, a partir de ese registro, que había similitudes entre los dos contextos educacionales y aún, por un lado, cierta idealización de la comisión río-grandense al modelo uruguayo y, por otro, la constatación de excelencia del método João de Deus utilizado en Río Grande del Sur.

Palabras-clave: misión educacional, Rio Grande del Sur, Uruguay.

\section{VOYAGE EDUCATIONNEL EN URUGUAY EM 1913: IMPRESSIONS DES PROFESSEURS RIO-GRANDENSES A PROPOS DES ECOLES DE MONTEVIDEO}

\section{Résumé}

Cet article analyse les impressions du groupe de professeurs rio-grandenses qui a voyagé, designé par les autorités de l'état, en Uruguay en 1913 qui avait pour but connître le système éducationnel uruguayen pour qualifier l'enseignement gaúcho. Ces enseignants ont enregistré leurs impressions et leurs observations à propos des visitations realisées aux institutions d'enseignement uruguayennes dans un Rapport Officiel composé de cinq parties. L'analyse de fond documentaire a remarqué, à partir de cet enregistrement, qu'il y avait des similitudes entre ces deux contextes d'éducation et encore d'un côté une certaine idéalisation de cette comission en relation au modèle uruguayen et d'un autre la constatation de l'excelence de la méthode João de Deus utilisée dans le Rio Grande do Sul.

Mots-clé: voyage educationnel, Rio Grande do Sul, Uruguay. 


\section{Introdução}

$\mathrm{O}$ presente artigo faz parte de uma investigação mais ampla que vem sendo realizada sobre a missão educacional enviada ao Uruguai em 1913 pela administração do governador Antônio Augusto Borges de Medeiros. A mesma tinha o intuito de analisar os modelos escolares, os métodos pedagógicos e outras questões relativas ao sistema de ensino uruguaio a fim de qualificar o sistema educacional do Rio Grande do Sul.

Com esse objetivo a missão foi realizada em dois momentos. No primeiro, em 1913, um grupo de professores da Escola Complementar de Porto Alegre ${ }^{2}$ permaneceu três meses em Montevidéo e foi liderado por Alfredo Clemente Pinto, diretor da referida instituição. O segundo momento, com duração de três anos, 1914 a 1916, possibilitou que um grupo de seis professoras fosse aperfeiçoar seus estudos no Instituto Nacional de Señoritas ${ }^{3}$ e praticar, nesse estabelecimento e na Escola de Aplicação da Capital uruguaia, os métodos de ensino lá utilizados.

Cabe salientar que essa estratégia adotada pelo governo gaúcho, na primeira década do século 20 , era uma prática que estava, de certa forma, consolidada, significando a possibilidade de obter maior qualidade e contribuir para solucionar problemas dos contextos educacionais do Estado. Por isso, muitas vezes, essas viagens foram incentivadas e financiadas pelo poder público.

Desse modo, copiar os modelos vigentes nos países ou Estados tidos como referência na época era compreendido como uma prática comum para aqueles que almejavam a qualificação de suas realidades educacionais já que as viagens permitiam olhares de familiaridade e estranhamento que tentavam "inspirar e legitimar mudanças" (Mignot e Gondra, 2007, p. 9) e "funcionavam como técnica de investigação e de conhecimento, como prática de observar, experimentar, comparar e produzir conhecimento sobre o outro" (Gondra, 2010, p. 13).

As impressões e observações dos comissionados, nesse contexto, eram peças fundamentais que possibilitavam análises e comparações. Assim, registrar as viagens pela escrita foi uma das estratégias encontradas para divulgar os modelos observados. Independentemente do documento - livros, relatórios oficiais, cartas e artigos em jornais ou revistas - a escrita passou a ser uma maneira de anunciar as impressões e as observações do lugar visitado a seu povo (Chamom e Faria Filho, 2007; Costa, 2003). Por essa razão, quanto mais informações e detalhes fossem descritos nos registros, mais ampliada seria a percepção sobre o outro e as possibilidades de intersecções entre os diferentes modelos.

Considerando, portanto, a relevância desses registros é que temos como objetivo analisar as impressões e observações do grupo de professores rio-grandenses que viajou, sob designação das autoridades gaúchas, ao Uruguai em 1913. Não abordaremos a atuação da segunda comissão enviada em 1914. Para tanto, foi analisado o relatório oficial de viagem enviado pelos professores ao dr. Firmino Paim Filho, diretor geral da Instrução Pública, e ao dr. Protásio Antônio Alves, secretário dos Estados dos Negócios do Interior e Exterior.

\footnotetext{
${ }^{2}$ Instituição estatal responsável pela formação de professoras no Rio Grande do Sul.

${ }^{3}$ Instituição estatal responsável pela formação de professoras no Uruguai. 
Vale destacar que esse documento é composto por cinco partes independentes que foram assinadas pelos professores responsáveis pelas visitas realizadas às escolas uruguaias e está anexado ao Relatório da Secretaria do Interior e do Exterior de 1914. É importante ressaltar que trabalhamos com o conjunto de relatórios e, por isso, no decorrer do texto o identificaremos como relatório de viagem.

A análise, de cunho documental, teve como suporte teórico, para a contextualização do Rio Grande do Sul, os trabalhos de Tambara (1995), Giolo (1997), Corsetti (1998), Peres (2000), Trindade (2001), e para o contexto uruguaio os de Bralich (1987), Barran (1998), Caetano (1998; 2011), Greissing (2000) e Palomeque (2012).

\section{O Rio Grande do Sul nas primeiras décadas do século 20}

Nas administrações republicanas durante o período da República Velha (18901930), o governo do Estado contou sempre com a participação efetiva do Partido Republicano Rio-Grandense - PRR -, ocupando o presidente do Estado a chefia do partido. No período aqui analisado foi presidente do Estado Antônio Augusto Borges de Medeiros.

As principais características do partido Republicano eram a defesa do federalismo, a ideologia positivista, inspirada em Augusto Comte, e a condenação do sistema escravocrata. Pautadas nessas premissas as ações desenvolvidas por este partido acarretaram mudanças significativas no Estado do Rio Grande do Sul no que tange à economia, à política e à cultura (Tambara, 1995; Giolo, 1997; Corsetti, 1998), uma vez que o projeto republicano tinha como objetivo eliminar todo e qualquer resquício do passado que fosse referente à estagnação, à escravidão e à ignorância.

Nesse sentido, o PRR rejeitava a velha ordem apresentando uma proposta que reorganizava a sociedade a partir da liberdade e da igualdade, propugnando que o progresso do Estado dependia de uma reforma intelectual e moral. Para por em funcionamento esse pressuposto Tambara (1995, p. 89) frisa que um dos "preceitos mais caros ao positivismo foi a criação de mecanismos de ação social que [engendrassem] a transformação da sociedade sem traumas violentos", o que implicava para o PRR investir em diferentes estratégias que buscassem a ordem social para, então, alcançar o progresso da sociedade".

Entendida por esse prisma a formação dos sujeitos passou a ser considerada indispensável à nova ordem. Logo, a escola pública primária "se transformou em instrumento fundamental da política do Estado gaúcho, para a consecução dos objetivos de modernização, em paralelo à garantia da estabilidade e do controle social" (Corsetti, 2000 , p. 2). Ainda segundo a autora, seria pela educação que os sujeitos poderiam sair da ignorância e serem educados de forma a ter aptidão para governar-se e adquirir o gosto pelo exercício da liberdade, além de adquirir a consciência nacional (Corsetti, 2000).

Assim, o governo passou a investir na expansão da escola pública e buscou supervisionar a atuação dos diversos agentes interessados em agir nessa área, procurando manter "uma posição equilibrada entre as participações da iniciativa privada, da municipalidade e do Estado" (Tambara, 1995, p. 281), uma vez que "todos apostavam na escola como a instituição ideal para implantar seu projeto social, e disputavam palmo a palmo, o espaço e o tempo da sala de aula" (Giolo, 1997, p. 20). 
Nesse contexto, Peres (2010) afirma que a criação dos colégios elementares estruturou um novo modelo escolar e uma nova cultura. Em 1909, com a criação dos mesmos, um modelo novo de escola primária começou a ser erguido, representando, na ótica das autoridades, uma superação das velhas e arcaicas escolas, que no geral funcionavam em uma única sala de aula e tendo apenas um professor, para o modelo da escola graduada. Nela uma nova forma escolar passa a vigorar: o ensino seriado, o funcionamento da escola em um único prédio, os novos métodos de ensino, o uso mais racional do material didático e a ampliação da escolarização da população gaúcha, entre outros.

Em síntese, a autora salienta que, diante dessa realidade educacional,

o certo é que os que estavam à frente da educação pública gaúcha fizeram um esforço nessa (re) organização do ensino primário para estabelecer um novo modelo de escola considerada mais moderna, mais eficiente, mais adequada a uma sociedade em mudança e especialmente mais adequada às "zonas de maior densidade demográfica. (Peres, 2000, p. 20).

Algumas das ações e investimentos do governo gaúcho no que diz respeito à instrução primária eram divulgadas, dentre outros impressos, no jornal $A$ Federação 4 . Essa era uma forma de o governo noticiar e informar à população o quanto o Estado vinha, ainda que em meio a dificuldades, investindo no que de mais atual e moderno existia na época para esse serviço. Fato esse que pode ser evidenciado por uma reportagem publicada no jornal no ano de 1913:

Vea o que de nós diz a citada revista Educação e Pediatria, de junho preterito, sob o titulo - A diffusão do ensino no Rio Grande do Sul: < O estado do Rio Grande do Sul está tambem compreendido no numero dos que se interessam alguma cousa pela instrucção do povo. E' uma prova disso a serie de providencias dessa natureza tomadas em fevereiro ultimo pelo governo daquelle prospero Estado, creando onze novos collegios elementares; requisitando a secretaria do Interior do seu collega das Obras Publicas, alguns engenheiros para projectarem os edifícios dos novos collegios e dirigirem a sua construcção, que breve começará. ( $A$ Federação, 8 out. 1913, p. 1$)^{5}$.

Assim como o excerto destacado outras reportagens publicadas no jornal $A$ Federação exaltavam ou buscavam afirmar, por cálculos e exemplos quantitativos, por exemplo, o quanto essa República vinha crescendo nos âmbitos educacional, político como econômico. Contudo, ainda que como salientado no excerto a expansão da instrução pública viesse ocorrendo e que colégios estivessem sendo construídos, é importante mencionar que um dos aspectos que foi compreendido, pelas autoridades, como fator de "estrangulamento do desenvolvimento da rede de ensino pública foi o processo de formação de professores" (Tambara, 1995, p. 284).

${ }^{4} \mathrm{O}$ jornal A Federação foi criado em Porto Alegre, em 1884, como um veículo de propagação das ideias defendidas pelo Partido Republicano Rio-Grandense.

${ }^{5}$ Foi respeitada a grafia da época. Hist. Educ. (Online) 
Além desse aspecto as autoridades da época enfatizavam que a falta de professores e a diversidade de métodos utilizados no ensino gaúcho também contribuíam para o não progresso e a pouca qualificação do ensino público.

Ainda que o governo tivesse, em 1897, estabelecido, por um regulamento, que o método a ser utilizado nas escolas públicas deveria ser o intuitivo e reafirmado tal decisão no Regulamento de 1906, Corsetti (2004) enfatiza que mesmo assim ainda havia certa dicotomia entre a orientação oficial do governo e a realidade da formação dos professores, uma vez que

enquanto o governo estabelecia por decreto a adoção do método indutivo, vinculado à perspectiva empirista, os professores guardavam, em função de sua formação recebida na Escola Normal, estruturada no Império quando a influência da Igreja Católica era determinante, uma orientação vinculada ao idealismo cristão de caráter dedutivista. (Corsetti, 2004, p. 9).

Nesse sentido é importante ressaltar que, embora a formação dos professores na Escola Complementar tenha substituído a de inspiração Católica, a pluralidade das formas de ensino ainda era muito presente no cotidiano dos colégios, tanto pelos diferentes processos de formação, quanto pela dificuldade do governo em inspecionar o que acontecia em cada escola. Para o PRR essa situação representava uma ameaça ao seu projeto político, pois se acreditava que a unidade do ensino poderia trazer progresso ao Estado, já que era concebida à época como uma necessidade dos povos cultos (Trindade, 2001).

A fim de superar essas e outras contingências relativas à instrução pública, diferentes medidas foram adotadas pelo governo gaúcho. Dentre elas, sob a administração de Borges de Medeiros, no ano de 1913, a organização de uma missão educacional ao Uruguai com o intuito de analisar a estrutura e o funcionamento do sistema escolar da referida República.

Desse modo, e especificamente sobre a estratégia adotada pelo governo gaúcho em 1913, ressaltamos que

o chamado intercambio de professores - diz a revista Educação e Pediatria, do Rio - vai já se generalizando entre os povos cultos, com excellentes resultados. São impressões novas e fecundas que se recebem, observações de valor que se colhem e idéas sãs que se trocam. Muito acertada, pois, deve ser julgada a medida que o nosso benemerito governo está a pôr em pratica. (A Federação, 8 out. 1913, p. 1).

A escolha do Uruguai como destino para a missão teve como principal justificativa das autoridades o fato de o país vizinho apresentar uma notável distinção entre os países latino-americanos. Sendo considerado uma República adiantada que vinha, nas primeiras décadas do século 20, obtendo cada vez mais um papel de destaque. Assim, consideramos pertinente apresentar na próxima seção uma caracterização do contexto uruguaio nesse período. 


\section{O contexto uruguaio}

Impulsionado pelo governo de Batlle y Ordónez $^{6}$ (1903-1907 e 1911-1915) ${ }^{7}$, o contexto uruguaio mostrou significativos avanços, tanto em termos econômicos, quanto educacionais, e passou, nas primeiras décadas do século 20 , a ter um papel de destaque na América Latina.

Batlle y Ordónez considerava-se um reformista e, portanto, negava a violência de uma revolução para as transformações almejadas. Por uma atitude paternalista, da atuação enquanto mediador nos intensos conflitos sociais que se produziram no início do século, enfrentamentos de trabalhadores e classe patronal, e também na atuação como propulsor de um desenvolvimento industrial voltado à substituição das importações, ele foi considerado como o principal intérprete dos novos tempos uruguaios (Bralich, 1987; Caetano, 1998, 2011; Greissing, 2000; Palomeque, 2012).

Nesse contexto, no plano social, por exemplo, houve um crescimento da população, assim como uma acelerada taxa de urbanização. No último quarto do século 19 a população duplicou, passando de 500.000 mil habitantes para 1.000 .000 , e no primeiro quarto do século 20 , atingiu a cifra de $1.500 .000^{8}$.

Nas primeiras décadas do século 20 o Uruguai iniciou um processo de laicização do ensino, passando a vigorar uma separação efetiva entre o poder do Estado e o poder religioso, com reflexos profundos no modelo educacional. A confrontação entre a Igreja e - Estado, pela ocupação de novos espaços públicos durante as últimas décadas do século 19 e as primeiras décadas do século 20, alcançou um limite pontual em $1919 \mathrm{com}$ a separação institucional de ambas. Contudo, essa solução política não dirimiu a questão religiosa no Uruguai. Pelo contrário, vários temas continuaram sendo motivo de debates, entre eles o da secularização e o da educação.

O processo de secularização uruguaio, fortemente estatal, cujos resultados mais notórios foram à privatização do religioso e a implantação gradual de uma religião civil laicizada, pretendia também definir os conflitos latentes sobre o ensino. Deste modo, se configurou um debate em que de um lado polemizaram liberais anticlericais, promotores do "monopólio estatal da educação", que privilegiavam as vias institucionais para fazê-lo, e, do outro lado, os católicos, que tendo como bandeira a "liberdade de ensino", defendiam a iniciativa privada e religiosa da educação, "intentando salvaguardar un espacio público ante el fuerte avance del proceso de secularización en la sociedad uruguaya" (Greissing, 2000, p. 69).

Tanto liberais anticlericais, quanto católicos manejavam argumentos na defesa de uma ou de outra posição. Afinal, para os contendores muitas coisas estavam em jogo: "nada más ni nada menos que la responsabilidad de la formación de la conciencia de los futuros ciudadanos" (La Tribuna Social, set. 1922, p. 19). As crianças apareciam como possíveis reféns de um Estado Liberal que, "disfrazado bajo el manto de la legalidad",

\footnotetext{
${ }^{6}$ Nasceu em Montevidéo. Formado em direito foi político e jornalista. Em 1886 fundou o diário El Dia e foi chefe político da província de Minas (1887), deputado pela província de Salto (1890-1893) e senador de Montevidéo (1899-1902) (Souza, 2003).

${ }^{7}$ No período de 1907 a 1911 assumiu a presidência Claudio William. Nesse período Batlle viajou para a Europa onde viu, na Suíça, o modelo de governo compartilhado, que foi defendido em seu segundo governo.

${ }^{8}$ Cabe destacar que este aumento populacional se vincula aos fluxos migratórios ocasionados pela Primeira Guerra Mundial. 
invadia a escola para convertê-los "en un centro de propaganda laica, atea, materialista" (La Tribuna Social, set. 1922) ${ }^{9}$, ou, ao contrário, como afirmavam os liberais, uma Igreja que claramente quer o domínio sobre as almas. É perceptível que nesse tópico educação - o enfrentamento entre o Estado e a Igreja não foi cordial.

Por sua vez, no plano cultural e educacional, uma significativa mudança nos primeiros anos do século 20 foi a expansão do sistema público de educação, que chegou a abarcar quase a totalidade da população. Como exemplos dos feitos nesse campo salientamos, em 1912, a criação de escolas secundárias departamentais e o livre acesso, em 1916, ao ensino secundário e superior.

No que tange ao ensino primário o crescimento da população escolar passou de 45.617 matriculados em 1897, para 74.717 em 1910, atingindo 157.300 no ano de 1930. O número de escolas para atender a essa população escolar cresceu também de 545 escolas em 1897 para 1.100 no ano de 1930. O número de professores também cresceu: de 2.300 em 1910 para 3.600 em 1930 (Bralich, 1987).

Nas primeiras décadas do século 20 as lideranças educativas, chefiadas pelo inspetor nacional de instrução primária, dr. Abel Pérez, compreendiam que a base fundamental de toda a educação estava alicerçada na escola e para que tivesse qualidade na mesma se fazia necessário ter bons professores, uma vez que "de la escuela primaria surge el verdadero y más sólido progreso de las naciones; es alli que se elabora y se prepara la evolución científica de la sociedad" (Memoria, 1904, p. 84). Percebe-se, nesse sentido, um investimento em defesa da escola como espaço que deveria ser frequentado por todos e que era fundamental à cultura do povo e ao progresso do Estado.

A fim de cumprir esse objetivo e de qualificar o setor educacional diferentes ações foram desenvolvidas, em especial envolvendo o ensino primário. Dentre elas destacamse: a melhoria no levantamento de dados estatísticos sobre as escolas, com a finalidade de um uso mais racional dos recursos humanos e financeiros; a adequação e aparelhamento das bibliotecas escolares, com novos aportes de obras didáticas, inclusive sendo a maior parte delas do exterior; a reorganização e ampliação dos programas escolares que estavam em vigência desde 1897; a ampliação e disseminação de Conferências $^{10}$, no que Carlos Vaz Ferreira desempenhou um papel relevante; a organização do Congresso de Inspetores em 1907; a criação de um corpo médico escolar, em 1908; a construção de prédios escolares; as missões encaminhadas ao Norte da América e à Europa para estudar aspectos pedagógicos, especialmente sobre o ensino técnico para mulher; a inauguração de escolas para atender especificidades de aprendizagens como, por exemplo, o Instituto para Surdos-mudos em 1909; reorganização do processo de formação docente (Araújo, 1911).

\footnotetext{
${ }^{9}$ Sobre o papel da imprensa nos conflitos sobre educação veja FERRETJANS, Daniel Álvarez. Historia de la prensa en el Uruguay. Montevideo: Busqueda/Fin de Siglo, 2008.

${ }^{10}$ As conferências eram destinadas aos professores com o intuito de criar uma unidade nos discursos e práticas desenvolvidas no ensino primário.

Hist. Educ. (Online) $\quad$ Porto Alegre v. 21 n. 51 Jan./abr., 2017 p. $253-270$
} 
Nesse período a formação de professores foi entendida como uma das peças fundamentais para o bom funcionamento e a qualidade de ensino, por isso, formar bons professores, era, conforme os discursos das autoridades, uma necessidade. Desse modo, "la acción del Estado era la única via para poder resolver las necessidades docentes que impedían la verdadera realización de un sistema público escolar" (Delio, 2009, p. 154) ${ }^{11}$.

Assim, a formação dos professores ocorria em duas instituições estatais de ensino normal, uma para homens e outra para mulheres, que contavam com uma escola prática anexa as mesmas. Os estudos nessas instituições tinham duração de dois anos e a idade mínima de ingresso era de 15 anos. Posteriormente passaram a ser de quatro anos de estudos gerais, posteriores ao primário, tendo certa equivalência aos estudos secundários. Essa nova estrutura, que estabelecia o título de maestro, eliminou a distinção anterior de professor de $1^{\circ}$ e $2^{\circ}$ grau, os quais deveriam desempenhar cargos nas escolas de $1^{\circ}$ e $2^{\circ}$ grau, respectivamente (Bralich, 1987) ${ }^{12}$.

Exposto esse panorama, passamos a apresentar a seguir a missão educacional de 1913 e as observações do grupo de professores rio-grandenses registradas no relatório de viagem.

\section{A viagem de 1913 ao Uruguai: as impressões e observações dos professores rio-grandenses}

No ano de 1913 um grupo de professores da Escola Complementar viajou a Montevidéo com o intuito específico de "estudar os methodos de ensino ali adoptados nas aulas publicas e tudo quanto diga respeito a esse importantíssimo ramo de serviço" ( $A$ Federação, $1^{\circ}$ set. 1913, p. 5). O grupo de professores foi liderado por Alfredo Clemente Pinto e era composto pelo professor Affonso Guerreiro Lima e pelas professoras Ondina Godoy Gomes, Georgina Godoy Moritz, Marieta de Freitas Chaves e Florinda Tubino.

O embarque desse grupo, em 15 de setembro de 1913, foi noticiado, tanto pela $A$ Federação, quanto pelo $O$ Correio do $P_{0 v o}{ }^{13} \mathrm{e}$, segundo as informações de ambos, estiveram presentes, para a despedida, autoridades como o dr. Protásio Antônio Alves e diversos professores e alunos da capital rio-grandense, o que pode indicar ter sido este um momento importante na ocasião.

Ao chegar em Montevidéo o grupo foi recepcionado no porto pelo inspetor uruguaio Luiz Pecantel, representante do governo uruguaio. As primeiras visitas da comissão foram conhecer a Direção Geral da Instrução Pública, encarregada do ensino primário no país, e a Comissão de Instrução do Departamento de Montevidéo.

Durante os três meses que permaneceu no país vizinho o grupo de professores teve a oportunidade de visitar diferentes estabelecimentos, entretanto, consta no relatório de viagem apenas o registro das visitas realizadas às escolas de Montevidéo. Considerando essas informações, apresentamos no quadro a seguir o cronograma de trabalho da comissão.

\footnotetext{
11 Salientamos que na literatura uruguaia Luis Maria Delio Machado é identificado nas citações como Delio, portanto, utilizaremos esse sobrenome.

12 Cabe destacar que, nesse período, o ensino primário uruguaio estava organizado em 3 graus: $1^{\circ}, 2^{\circ}$ e $3^{\circ}$ grau.

13 O jornal foi criado em 1895, em Porto Alegre, por Francisco Antonio Vieira Caldas Júnior e, segundo constava em suas próprias edições, se caracterizava por ser um jornal informativo. 
Quadro 1 -

Cronograma de trabalho do grupo de professores.

\begin{tabular}{|c|c|c|}
\hline Data & Escola & Subgrupo \\
\hline \multirow[t]{2}{*}{ 24/09 à 04/10 } & Escola de $1^{\circ}$ grau $n^{\circ} 2$ & $\begin{array}{l}\text { Georgina Godoy Gomes, Ondina } \\
\text { Godoy Moritz e Affonso Guerreiro } \\
\text { Lima. }\end{array}$ \\
\hline & Escola de $1^{\circ}$ grau $n^{\circ} 9$ & $\begin{array}{l}\text { Clemente Pinto, Florinda Tubino e } \\
\text { Marietta Freitas Chaves. }\end{array}$ \\
\hline \multirow{4}{*}{ 07/10 à 24/10 } & Colégio de $2^{\circ}$ grau $n^{\circ} 27$ & $\begin{array}{l}\text { Marietta Freitas Chaves e Florinda } \\
\text { Tubino. }\end{array}$ \\
\hline & Colégio de $2^{\circ}$ grau $n^{\circ} 5$ & $\begin{array}{l}\text { Georgina Godoy Gomes, Affonso } \\
\text { Guerreiro Lima. }\end{array}$ \\
\hline & Colégio de $3^{\circ}$ grau $n^{\circ} 2$ & $\begin{array}{l}\text { Marietta Freitas Chaves e Florinda } \\
\text { Tubino. }\end{array}$ \\
\hline & Colégio de $3^{\circ}$ grau $n^{\circ} 1$ & $\begin{array}{l}\text { Georgina Godoy Gomes, Ondina } \\
\text { Godoy Moritz, Affonso Guerreiro } \\
\text { Lima. }\end{array}$ \\
\hline $04,05,06$ e $07 / 11$ & $\begin{array}{l}\text { Escola de Aplicação anexa à } \\
\text { Escola Normal de Moças }\end{array}$ & Relatório assinado por todos \\
\hline $10,11,12 / 11$ & Jardim de Infância & Relatório assinado por todos \\
\hline 13 e $14 / 11$ & Asilo Maternal & Relatório assinado por todos \\
\hline $17 / 11$ & Escola ao Ar Livre & Relatório assinado por todos \\
\hline \multirow[t]{2}{*}{ 19/11 } & Instituto dos Surdos-Mudos & Relatório assinado por todos \\
\hline & Biblioteca e Museu Pedagógico & Relatório assinado por todos \\
\hline
\end{tabular}

Fonte: Quadro organizado a partir dos dados apresentados no relatório de viagem, 1914.

Como pode ser observado a partir do quadro o professor Clemente Pinto dividiu a comissão em dois grupos. O primeiro era composto por Alfredo Clemente Pinto, Marieta Chaves e Florinda Tubino e teve durante as visitas o acompanhamento do inspetor uruguaio Luiz Pencatel. O segundo foi constituído por Georgina Godoy Gomes, Affonso Guerreiro Lima e Ondina Godoy Moritz e foi acompanhado por Marieta Garcia de San Martin, também inspetora uruguaia. Todavia, como também pode ser evidenciado pelos dados do quadro, inferimos que as últimas seis instituições tenham sido visitadas por todo o grupo de rio-grandenses, em virtude de as escolas serem únicas e consideradas modelo no país.

Com o intuito de manter o governo gaúcho informado sobre o trabalho que estava sendo desenvolvido em Montevidéo, cada grupo deveria organizar um relato semanal das atividades realizadas para ser enviada ao secretário Protásio Alves. A sequência em que essas observações foram publicadas nos jornais rio-grandenses $A$ Federação e o Correio do Povo nos possibilita constatar que esses registros foram enviados de forma separada e, posteriormente ao recebimento das correspondências, as autoridades gaúchas tenham as anexado compondo um único relatório, o qual foi disponibilizado no relatório da Secretaria dos Negócios do Interior e Exterior do ano de $1914^{14}$.

\footnotetext{
${ }^{14}$ Foram realizadas pesquisas no Arquivo Histórico de Porto Alegre a fim de encontrar outras correspondências que possivelmente tenham sido trocadas entre as autoridades gaúchas e o grupo de professores, contudo, nenhum material foi localizado. Hist. Educ. (Online) $\quad$ Porto Alegre v. 21 n. 51 Jan./abr., 2017 p. $253-270$
} 
Nesse relatório de viagem, composto por cinco partes, foram descritas inúmeras facetas do funcionamento do sistema educacional uruguaio, tais como a infraestrutura das instituições, a organização administrativa e pedagógica, os programas e métodos de ensino utilizados, as questões de disciplina e de ordenamento, a formação de professores. É importante salientar que essas anotações e registros é uma versão, pois,

viajar, além de comparar, também é refletir. É estar com os olhos aguçados e os ouvidos bem abertos para recolher impressões produzidas por estes sentidos, a visão e a audição, permitindo um constante pensar o "eu" e o "outro", o igual e o diferente, e buscar compreender o porquê das diferenças. O que cada um observa e registra é resultado da maneira, do lugar e do momento situacional que se escolhe ver. Nesse olhar, muitas vezes, estão embutidas crenças culturais, religiosas, costumes, hábitos, formas de ser, de agir e sentir, tensões, opiniões, desejos e sentimentos. O olhar não é linear, tem muitas direções, curvas e obstáculos. (Cardoso, 2011, p. 28).

Desse modo, é preciso compreender que o documento apresentado pelos comissionados não trata de "dizer o que houve", mas sim de narrar "o que o autor diz que viu, sentiu e experimentou, retrospectivamente, em relação a um acontecimento" (Cardoso, 2011, p. 29) e, portanto, devemos entender a fonte escrita como um registro produzido pelos autores a partir de suas impressões e do seu ponto de vista. Há de se considerar, ainda, o fato de que o "sujeito escreve para um determinado fim, a partir de efeitos que quer provocar" seja no sentido de afirmar, criticar ou negar o que foi observado (Cardoso, 2011, p. 86).

Nesse sentido, é importante relembrar que a missão foi organizada em um período em que o sistema educacional público gaúcho estava em expansão e consolidação. Logo, é preciso considerar que os registros dos professores, nesse contexto, poderiam tanto corroborar as práticas pedagógicas que vinham sendo desenvolvidas no Estado, quanto também refutá-las ou indicar a necessidade de aperfeiçoá-las.

Considerando essas questões, a partir da leitura do relatório de viagem organizamos as observações e as impressões dos professores em quatro categorias: elogios tecidos ao sistema uruguaio; similaridades entre os dois sistemas; críticas ao ensino uruguaio e aspectos que poderiam ser colocados em funcionamento no sistema educacional gaúcho.

A partir da análise documental evidenciamos que os principais elogios feitos pela comissão de professores rio-grandenses ao sistema uruguaio foram relativos à infraestrutura dos prédios de $1^{\circ} \mathrm{grau}$, adequada às exigências da higiene e da Pedagogia e, ainda, sobre os espaços físicos dos prédios: tamanho, localização, qualidade, pátios, as salas de aula, claridade etc.; à presença de cartazes com preceitos de civilidade e moral em todas as instituições visitadas, bem como ao disciplinamento dos alunos, ao controle efetivo por parte das autoridades, à força e implantação de um nacionalismo de cunho cívico e patriótico: marchas de fundo militar, cantos patrióticos, hinos à bandeira, filas e obediência aos toques de sinetas, etc.; ao fato de os diretores atuantes em escolas com frequência maior de 200 alunos não terem a incumbência de ministrar aulas; ao controle do conteúdo trabalhado em sala de aula pelo uso do diário do professor em que deveriam ser registradas as lições que seriam estudadas no dia seguinte; ao ensino da geometria com papéis recortados, sólidos em madeira e papelão; ao entendimento mais 
ampliado acerca do método de lições de coisas, que na prática era utilizado com a intenção de tornar as crianças mais observadoras; ao número máximo de 50 alunos nas classes do ensino primário e de 30 nas classes preparatórias para analfabetos; às características dos professores, tais como um grande espírito de observação, larga experiência e muita paciência e ao preparo sólido dos professores.

Sobre esse último elogio traçado ao sistema uruguaio ressaltamos que os professores destacaram ser

\begin{abstract}
deveras admirável ouvir uma destas senhoritas, ás vezes, quasi tão joven como as próprias alumnas, dissertar com toda proficiencia sobre um thema qualquer e, com toda firmeza, encaminhar as creanças no descobrimento da verdade que lhes quer transmitir! Provem, sem duvida, este resultado do severo regimen de estudo a que estão sujeitos os candidatos ao magisterio, regimen de que não é de opportuno occupar-nos agora, e das severissimas provas a que são submetidos. (Relatório de viagem, 1914, p. 208).
\end{abstract}

As impressões apresentadas demonstram um conjunto de aspectos considerados como exemplares, seja relativo à didática de ensino, à organização didático-pedagógica, à infraestrutura ou à disciplina, como também à formação de professores. Nesse sentido, destacamos que houve certa idealização do modelo uruguaio em detrimento do sistema educacional gaúcho.

Além desses destaques também foi registrado, pelos professores, que existiam similaridades entre o sistema de ensino uruguaio e o gaúcho, o que, segundo tais registros, corroborava a assertiva das autoridades gaúchas de que o Rio Grande do Sul possuía elementos de uma educação moderna.

Assim, foi salientado no relatório de viagem que, tanto no Rio Grande do Sul, quanto no Uruguai, a elaboração do horário das classes primárias era feita pelos professores e submetida à aprovação dos diretores. E ainda que o mobiliário escolar, em ambos os casos, era importado dos Estados Unidos da América.

No que tange ao ensino a comissão registrou que a leitura no $1^{\circ}, 2^{\circ}$ e $3^{\circ}$ ano se desenvolvia no país vizinho da mesma forma que no Rio Grande do Sul, pois primeiro as crianças liam e comentavam para depois fazerem a leitura mecânica. A escrita, por sua vez, acompanhava a leitura e os exercícios de caligrafia e, assim como no Rio Grande do Sul, eram empregados no Uruguai os cadernos Garnier $^{15}$.

Para além dos elogios e das similaridades os professores teceram algumas críticas ao sistema uruguaio o que, por sua vez, designava o Rio Grande do Sul como mais qualificado em alguns aspectos. No ensino da aritmética foi destacado que no Uruguai não se ensinava as quatro operações simultaneamente, "o que tantos e bons resultados nos têm dado" (Relatório de viagem, 1914, p. 178). Ainda foi salientado que o ensino dessa matéria no $4^{\circ}$ ano, no Uruguai, era muito vasto, dificultando a aprendizagem das crianças.

${ }^{15}$ Cadernos utilizados principalmente como suporte de práticas de escrita. Hist. Educ. (Online) Porto Alegre v. 21 n. 51 Jan./abr., 2017 p. $253-270$ 
Constatamos, ainda, que foi reincidente em todas as cinco partes do relatório de viagem a observação dos professores indicando que o método utilizado para o ensino da leitura nas classes preparatórias, ministradas para analfabetos no Uruguai, era inferior ao método João de Deus ${ }^{16}$ utilizado no Rio Grande do Sul.

A seguir, expomos um trecho sobre essa ressalva feita pelos professores:

O méthodo adoptado no ensino é o phonético (analytico-synthetico) [...] não é methodo novo e já foi combatido com grande superioridade de vistas pelo incomparavel pedagogo João de Deus cujo methodo, agora, mais do que nunca, reconhecemos ser imitavel e inexcedivel. Os resultados o privam: com o systema de João de Deus conseguimos, nas nossas aulas, em 3 mezes, ensinar uma turma de 60 alumnos a ler com acerto e firmeza, sabendo dar a razão do que lê, ao passo que com o systema phonetico, nas aulas d'aqui, que não excedem de 30 alumnos, ainda depois de 6 mezes, a creança titubeia na leitura e, ás vezes, chega a ler palavras que não estão escriptas, o que prova que o resultado desse ensino é, em grande parte, um esforço de memoria. (Relatório de viagem, 1914, p. 177).

Contudo, referindo-se a essa crítica o secretário Protásio Alves anunciou que "isso, porém, não diminue a sincera admiração que os mesmos professores tributam á organisação do ensino na culta Republica e ao esmerado preparo que recebem seus professores nas Escolas Normais e de Applicação" (Mensagem, 1914, p. 17).

O secretário frisou, ainda, que apesar dos pormenores, a missão educacional vinha acentuar as vantagens que colhe o profissional com o estudo em meios diferentes, pois "mesmo em caso de superioridade do systema do observador, ele pode ser melhorado em detalhes". Desse modo "as observações da missão escolar serviram para confirmar a excelência dos methodos aqui adoptados, ao mesmo tempo em que inspiraram a adoção de regras novas em questão de detalhes" (A Federação, 5 nov. 1914, p. 8).

Nesse sentido, evidenciamos que o grupo de professores indicou, no decorrer do relatório de viagem, que alguns detalhes relativos ao ensino poderiam ser postos em funcionamento no sistema educacional gaúcho. Esses aspectos foram salientados também em uma das reportagens publicadas no jornal $A$ Federação que buscava apresentar para a sociedade gaúcha os resultados da missão:

A missão riograndense entende, porem, que seria de grande proveito acrescentar ao nosso systema alguns pontos do Uruguay; um delles, por exemplo, é dar a idéa de dezena assim que a creança conheça o número dez, pois ha mais difficuldade em ensinar depois, como se faz aqui. $O$ estudo de geometria, começa pelas noções de forma, servindo-se o professor de sólidos e objectos da escola. Ministram-se noções sobre o

\footnotetext{
16 João de Deus nasceu em 1830, em Portugal. Fez faculdade de Direito, mas não exerceu a função. Foi poeta e criou a cartilha de leitura e escrita Maternal. Sua cartilha foi publicada em 1876 e logo se espalhou por Portugal (Trindade, 2001). A cartilha estava estruturada em 25 lições com uma nota introdutória e três anexos: uma lista de palavras esdrúxulas, os alfabetos minúsculo e maiúsculo e o poema Hino de amor. Cada lição tem uma introdução de natureza didática e uma lista de letras e palavras. As características inovadoras do método foram a supressão da apresentação do alfabeto completo como ponto de partida do ensino; diferente seriação das letras; uso dos tipos liso e lavrado na apresentação gráfica das sílabas, evitando o desmembramento das palavras; substituição da soletração pelo método da silabação; eliminação das sílabas mortas; nova nomenclatura das letras (Dicionário de educadores portugueses).
} 
corpo humano, sobre animaes e plantas. Quanto aos animaes, servem de objecto os mais conhecidos das creanças, indicando-se os seus costumes mais interessantes e os serviços que prestam. (A Federação, 7 nov. 1913, p. 1).

Com a mesma intencionalidade, porém referente à formação de professores, foi indicada a necessidade de ter pessoas preparadas pedagogicamente para assumir as aulas da Escola Complementar, o que incidiria em uma melhor qualificação daqueles que almejavam o magistério no Estado.

Os professores rio-grandenses salientaram, ainda,

a conveniencia de destinar o curso elementar, anexo á nossa Escola Complementar, exclusivamente a esse fim, isto é, ao aprendizado, ao preparo pedagógico pratico dos nossos alumnos-mestres. É sobretudo alli, nesse curso, que os futuros professores se hão de forma. (Relatório de viagem, 1914, p. 219).

Essa observação, de certa forma, reafirmava a importância e valorização das práticas de ensino realizadas nas escolas anexas no processo de formação docente.

É importante frisar que foi recorrente no relatório de viagem, ao fazer referência aos professores e o processo de formação docente, o uso de expressões como: professoras à altura de sua nobre missão, preparo pedagógico, grande habilidade, amor e dedicação ao magistério; o que indica uma caracterização de excelência ao corpo docente uruguaio e ao curso realizado pelos aspirantes à profissão do magistério.

Em consonância com as indicações dos professores rio-grandenses, de que alguns aspectos poderiam ser adotados no sistema de ensino gaúcho, localizamos no relatório da Secretaria de 1914 a assertiva de que "após cuidadosa observação, revelada pelos seus relatorios, veio a commissão pôr em pratica na Escola [Complementar], melhoramentos na technica do ensino, de real valor" (Relatório, 1914, p. 8).

$\mathrm{Na}$ mensagem encaminhada à Assembleia, ainda no ano de 1914, consta o pronunciamento das autoridades de que "a commissão de professores, encarregados de estudar os progressos da instrucção na capital uruguaya, dali trouxe precioso cabedal de observações e melhoramentos que vão sendo aproveitados no ensino da Escola Complementar" (Mensagem, 1914, p. 17).

Entretanto, não localizamos, no relatório da Secretaria dos Negócios do Interior e do Exterior, nas mensagens e nem nas reportagens publicadas nos dois periódicos citados anteriormente referências de quais aspectos e elementos da cultura escolar uruguaia teriam sido adotados na Escola Complementar de Porto Alegre. Observamos, nesses três materiais, apenas a indicação de que os detalhes do sistema uruguaio estavam sendo incluídos nos fazeres da Escola Complementar, que abarcava também a escola anexa.

A consideração de que na época o ensino ministrado nessa instituição era compreendido como exemplar para as práticas realizadas nas demais escolas públicas nos possibilita duas hipóteses. A primeira está relacionada à intenção de que ao adotar, nessa instituição, alguns aspectos do sistema uruguaio, essas mudanças serviriam como modelo para as demais. E a segunda é a de que esses elementos foram, em carácter experimental, utilizados primeiro na Escola Complementar para, posteriormente, serem adotados no sistema público. 
As justificativas apresentadas pelos professores rio-grandenses no relatório de viagem demonstram, de certa forma, que alguns aspectos do sistema uruguaio foram sendo indicados por eles para serem incluídos na realidade educacional gaúcha por corroborarem e reafirmarem o ideal defendido pelos republicanos de controlar e fiscalizar, não só o trabalho do professor, mas também o que estava sendo ensinado nas escolas públicas. Observa-se, nesse sentido, a relevância desse anseio para o momento em que o Rio Grande do Sul encontrava-se de expansão e consolidação de um sistema público de ensino.

São válidas, desse modo, as palavras do professor da Escola Complementar Oswaldo Vergara em uma reportagem publicada no jornal $A$ Federação em que defendia a missão de 1913: "Convém dizer que a missão não vai ali estudar a organização das escolas uruguaias, para, depois, segundo as observações, colhidas, modelar a nossa instrução. Vai apenas melhorar o seu cabedal" (A Federação, 9 set. p. 3).

\section{Conclusão}

A missão educacional enviada ao Uruguai em 1913 tinha como intuito geral acompanhar o modelo de ensino vigente naquele país. Para tanto, as autoridades do Rio Grande do Sul designaram para essa missão um grupo de professores que atuava na Escola Complementar, lugar legitimado à época como um centro difusor dos saberes pedagógicos. Assim, evidenciamos que as autoridades gaúchas não apenas contaram com um qualificado grupo de professores, como também com a presença do diretor da Escola Complementar, no caso Alfredo Clemente Pinto.

A partir da leitura do relatório de viagem organizamos as observações dos professores em quatro categorias: elogios tecidos ao sistema uruguaio; similaridades entre os dois sistemas; críticas ao ensino uruguaio e aspectos que poderiam ser colocados em funcionamento no sistema educacional gaúcho.

A análise dessas categorias evidenciou que, por um lado, houve, sob a perspectiva da comissão, certa idealização do modelo de ensino uruguaio em comparação ao modelo do Rio Grande do Sul como, por exemplo, nos aspectos referentes à infraestrutura, à disciplina, à preparação de formação de professores e didático-pedagógicos. Por outro lado foram destacadas algumas vantagens do sistema gaúcho em relação ao país vizinho confirmando que o Rio Grande do Sul demonstrava avanços em seu sistema educacional, já que o método de ensino utilizado para a leitura e para o ensino da aritmética era mais qualificado.

Constatamos, ainda, que os elogios tecidos à estrutura educacional uruguaia corroboravam a proposta defendida pelos dirigentes do Estado de progresso pela ordem e pela educação, bem como reafirmavam a importância do caráter prático na formação dos professores.

Certamente diversos dos aspectos descritos como exemplares pelo grupo de professores tenham trazido implicações para o campo da educação do Rio Grande do Sul. Por ora identificamos, como assinalado por Protásio Alves, que algumas questões práticas e didático-pedagógicas começaram a ser utilizadas na Escola Complementar de Porto Alegre, o que evidencia que as primeiras apropriações foram feitas no curso que qualificava os professores primários e que na época era tida como modelo para as demais escolas do Estado. 
Ainda que em detalhes as reorganizações propostas a partir de diferentes missões e experiências são importantes para compreender as diferentes relações que concorreram para a constituição do sistema de ensino público do Rio Grande do Sul.

\section{Referências}

ARAÚJO, Orestes. Historia de la escuela uruguaya. Montevideo: El Siglo llustrado, 1911. BRALICH, Jorge. Breve historia de la educación en el Uruguay. Montevideo: Nuevo Mundo, 1987.

CAETANO, Gerardo. Lo privado desde lo público: ciudadanía, nación y vida privada en el Centenario. In: BARRÁN, José Pedro; CAETANO, Gerardo; PORZECANSKI, Teresa. (dir.). Histórias de la vida privada en el Uruguay. Tomo 3. Individuo y soledades (19201990). Montevideo: Santillana, 1998.

CAETANO, Gerardo. La república batllista. Montevideo: Banda Oriental, 2011.

CARDOSO, Silmara de Fátima. Viajar é inventar o futuro: narrativas de formação e o ideário educacional brasileiro nos diários e relatórios de Anísio Teixeira em viagem à Europa e aos Estados Unidos (1925-1927). São Paulo: USP, 2011. 156f. Dissertação (mestrado em Educação). Programa de Pós-Graduação em Educação, Universidade de São Paulo.

CHAMON, Carla Simone; FARIA FILHO, Luciano Mendes de. A educação como problema, a América como destino: a experiência de Maria Guilhermina. In: MIGNOT, Ana Chrystina Venâncio; GONDRA, José Gonçalves (orgs.). Viagens pedagógicas. São Paulo: Cortez, 2007, p. 39-64.

CORSETTI, Berenice. Controle e ufanismo: a escola pública no Rio Grande do Sul (1889/1930). Santa Maria: UFSM, 1998. 537f. Tese (doutorado em Educação). Programa de Pós-Graduação em Educação, Universidade Federal de Santa Maria.

CORSETTI, Berenice. O positivismo como base do pensamento educacional no Rio Grande do Sul (1889/1930). ANPED SUL, 5, 2004. Anais ... Paraná: PUCPR, 2004. Disponível

em http://www.portalanpedsul.com.br/admin/uploads/2004/Painel/Painel/11 5859 O POSITI VISMO COMO BASE DO PENSAMENTO EDUCACIONAL NO RIO GRA.pdf. Acesso em 10 abr. 2015

CORSETTI, Berenice. A construção do cidadão: os conteúdos escolares nas escolas públicas do Rio Grande do Sul na Primeira República. Hist. Educ. (Online), Porto Alegre, v. 4, n. 8, 2000, p.175-192.

COSTA, Wilma Peres. Viagens e peregrinações: a trajetória de intelectuais de dois mundos. In: BASTOS, Elide; RIDENTI, Marcelo; ROLAND, Denis (org.). Intelectuais: sociedade e política. São Paulo: Cortez, 2003, p. 57-84.

DELIO MACHADO, Luis María. Historia de la formación docente: la enseñanza normal nacional. Montevideo: Cruz del Sur, 2009.

GIOLO, Jaime. Estado, igreja e educação no Rio Grande do Sul da primeira república. São Paulo: USP, 1997. 429f. Tese (doutorado em História e Filosofia da Educação). Faculdade de Educação, Universidade de São Paulo.

GONDRA, José. Apresentação. In: Revista Brasileira de História da Educação. São Paulo, SBHE, v. 10, n. 22, 2010, p.13-16. 
GREISSING, Carolina. Conflictos y tensiones en el debate por la educación durante el Centenario (1910-1934). In: CAETANO, Gerardo. Los uruguayos del centenario: nación, ciudadanía, religión y educación (1910-1930). Montevideo: Banda Oriental, 2000.

MEMORIA correspondente á los años de 1902-1903 presentada a la Dirección General de Instrucción Primaria y ao Ministerio do Fomento por Abel J. Pérez, Inspetor Nacional. Montevideo: Talleres Gráficos A. Barreiro y Ramos, 1904.

MENSAGEM enviada a Assembléa dos Representantes do Estado do Rio Grande do Sul, pelo Presidente Borges de Medeiros, em 1914. Porto Alegre: Officinas graphicas d' "A Federação", 1914.

MIGNOT, Ana Chrystina Venâncio; GONDRA, José Gonçalves (org.). Viagens pedagógicas. São Paulo: Cortez, 2007.

NÓVOA, António (dir.). Dicionário de educadores portugueses. Porto: Asa, 2003.

PALOMEQUE, Agapo Luis. La educación primaria entre 1886 y 1900. In: PALOMEQUE, Agapo Luis (org.). Historia de la educación uruguaya: la educación uruguaya 1886-1930. Tomo III. Montevidéo: La Plaza, 2012, p. 25-58.

PERES, Eliane Teresinha. Aprendendo formas de pensar, sentir e de agir. a escola como oficina da vida: discursos pedagógicos e práticas escolares da escola pública primária gaúcha (1909-1959). Belo Horizonte: UFMG, 2000. 493f. Tese (doutorado em Educação). Programa de Pós-Graduação em Educação, Universidade Federal de Minas Gerais.

PERES, Eliane Teresinha. A escola graduada no Rio Grande do Sul no início do século 20: a implantação de um novo modelo e de uma nova cultura escolar. In: VIDAL, Diana Gonçalves; SCHWARTZ, Cleonora Maria. (org.). História das culturas escolares no Brasil. Vitória: UFES, 2010.

PORTO ALEGRE. A Federação. Disponível em:

<http://memoria.bn.br/DocReader/docreader.aspx?bib=388653\&pesq=>. Acesso em 10 mar. 2014.

PORTO ALEGRE. Correio do Povo. Edições de 1913 disponíveis no Núcleo de Pesquisa em História da Universidade Federal do Rio Grande do Sul.

RELATÓRIO apresentado ao Ex. Sr. Dr. A. A. Borges de Medeiros, Presidente do Estado do Rio Grande do Sul pelo Dr. Protasio Antonio Alves, Secretario de Estado dos Negocios do Interior e Exterior em 08 de setembro de 1914. Porto Alegre: Off. Graphicas da Casa de Correção, 1914.

RELATÓRIO DE VIAGEM apresentado ao Ex. Sr. Dr. Protasio Antonio Alves, Secretario de Estado dos Negocios do Interior e Exterior pelo Dr. Firmino Paim Filho, Diretor Geral em 30 de agosto de 1914. Porto Alegre: Off. Graphicas da Casa de Correção, 1914.

SOUZA, Marcos Alves de. A cultura política do batllismo no Uruguai (1903-1958). São Paulo: Annablume/Fapesp, 2003.

TAMBARA, Elomar. Positivismo e educação: a educação no Rio Grande do Sul sob o castilhismo. Pelotas: UFPel, 1995.

TRINDADE, Iole. A invenção de uma nova ordem para as cartilhas: ser maternal, nacional e mestra: queres ler? Porto Alegre: Ufrgs, 2001. 524f Tese (doutorado em Educação). Universidade Federal do Rio Grande do Sul, Faculdade de Educação. 
CAROLINE BRAGA MICHEL é estudante do curso de doutorado no Programa de Pós-Graduação em Educação da Universidade Federal de Pelotas. Mestre em Educação em Ciências pela Universidade Federal do Rio Grande.

Endereço: Av. Fernando Osório, 4090, - 96065-040, Pelotas - RS - Brasil.

E-mail: caroli brga@yahoo.com.br.

EDUARDO ARRIADA é professor adjunto de História da Educação na Universidade Federal de Pelotas e Integrante do Centro de Investigações em História da Educação - Ceihe.

Endereço: Rua D. Pedro II, 414 - 96010- 300 - Pelotas - RS - Brasil.

E-mail: earriada@hotmail.com.

Recebido em 11 de dezembro de 2015.

Aceito em 6 de junho de 2016. 